\title{
The Study on College Students' Learning Initiatives in Ethnic Minority Concentrated Areas - Taking Xinjiang University as an Example
}

\author{
Qiu Tao ${ }^{1, a}$ \\ ${ }^{1}$ Office of registry of Xinjiang University, Urumqi, China \\ akskxju@xju.edu.cn
}

\begin{abstract}
With the reform of the current education system, self-learning mode is widely recognized, independent study has also been defined as the ideal goal of education is no exception in remote ethnic areas. This article will research the initiative for college students in minority areas, in order to improve national College Students self-learning ability.
\end{abstract}

Keywords: Ethnic minority concentrated areas, Initiative, The education study

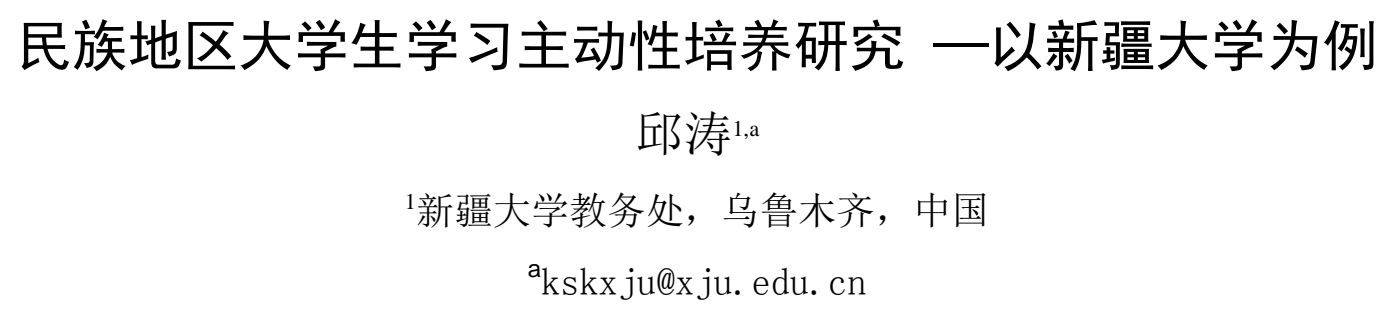

中文摘要: 随着当前教育体制的改革, 自主 学习的学习模式引起广泛认同, 自主学习也 被定义为教育的理想目标, 边远民族地区也 不例外, 本文将针对民族地区大学生的学习 主动性进行研究, 以期提高民族地区大学生 的自我学习能力。

关键词: 民族地区, 主动性, 教育研究

\section{一、引言}

人才资源是当代经济社会发展的第一 资源, 优先发展人才资源是许多国家实现经 济追赶的成功经验。《国家中长期人才发展 规划纲要 (2010--2020)》中提出了人才优 先发展的指导方针, 确立了人才在整个经济 社会发展战略布局中处于优先发展的重要 位置。未来发展的关键靠人才, 人才培养的 基础在教育, 自主学习也随之被很多高校教
育工作者确立为重要研究课题, 学习主动性 作为自主学习的前提和动力, 在教育与被教 育者群体中, 研究大学生主动性学习情况及 实施策略是非常有必要的。

民族大学生的高等教育是我国高等教 育的重要组成部分, 自国家实施西部大开发 战略以来, 国家在高等教育和师资培训方面 给予西部省份极大的支持, 新疆教育事业已 进入快速发展的重要战略机遇期。新疆大学

(以下简称我校) 作为新疆维吾尔自治区

(以下简称我区) 高等教育的重要基地, 作 为国家211工程院校, 对我校大学生的自主 性学习现状、问题及应对措施等方面的研究 就带有典型意义了, 本文针对民族地区大学 生高校学习现状展开探讨, 以期获得民族地 区大学生教育的良好学习模式。 


\section{二、民族地区大学生学习主动性问题提出}

培养大学生学习的主动性是我区社会 经济发展的需要, 方方面面的社会竞争, 促 使我们必须认识到, 我区各类人才是否具有 竞争力, 是否具有巨大潜力, 是否具有在信 息时代轻车熟路地驾驭知识的本领, 是否胜 任各行各业, 从根本上讲, 大学生离开校园 以后, 成败与否完全取决于大学生是否具有 自主学习的能力, 自主学习已成为 21 世纪人 类生存的一项基本能力。

就我区高校大学生而言, 近年入校大学 生都是我国高中普及新一轮的基础教育课 程改革后升入大学的, 都不同程度地体验过 自主探究学习的过程。尽管如此, 作为综合 性大学, 我校大学生的性别、民族、专业及 接受基础教育的地域、教育环境等多种因素 都使我校大学生群体学习主动性和学习能 力上有明显差异。由于我区有 13 个少数民 族, 较为典型的多元文化和多种语言的社会 背景, 各民族在形成和发展中, 受其所处的 独特地域、意识形态和风土人情等诸多因素 的影响, 形成了本民族特有的文化体系。我 区民族大学生在文化适应上表现的更为敏 感, 他们从自己熟悉的母语文化进入一个崭 新汉语环境后, 首先不得不面对语言沟通及 跨文化适应的考验, 其次, 民族学生的思维 方式深受本民族文化的影响, 而我区作为教 育相对落后地区, 在强调教学的规范化、标 准化的同时, 这也无形之中忽视了民族的差 异性, 从而增加了民族学生学习的难度。对 民族学生在学习上存在的特殊性, 作为教育 工作者, 在教学实践中, 教师要充分考虑, 细心揣摩，从实际出发，激发民族学生的 学习主动性, 勇于上进, 勤于好学。

\section{三、民族地区大学生学习主动性现状}

我校汉语言理工科班级中民族学生约 占班级人数的 $15 \%-25 \%$ 左右, 班级教学面临 的情况复杂, 为此, 我们在认真分析影响学 生学习主动性因素的基础上, 精心设计了调 查问卷, 在我校学生中发放 2000 份问卷 (其 中汉族学生697份, 少数民族学生525份), 回收问卷1750份, 有效问卷 1724 份, 有效率 $98.5 \%$ 。通过对我校 1724 名学生 (来自 14 个 学院) 的调查问卷, 利用SPSS软件统计, 从
调研结果来看, 我校大学生学习主动性有待 提高, 其中民族学生更应提高其自身自主学 习的能力。

根据调查问卷, 我校大学生学习主动性现状 如下:

(1) 学习原动力不足, 主动学习意志薄弱。 对于大学期间的发展目标, 大一学生中 $41 \%$ 的学生 (其中民族学生占 $18 \%$ ) 认为是提 高自身素质, 为实现理想作好准备; 52\%的 学生（其中民族学生占 $23 \%$ ）认为是掌握一 技之长, 为就业打好基础; 另有 $7 \%$ 的学生没 有具体目标。对课堂教学内容不吸引时, 只 有 $28 \%$ 的学生（其中少数民族学生占 $10 \%$ ）的 态度是加倍集中精力与老师思路保持一致; 高达 $65 \%$ 的学生（其中民族学生占 $45 \%$ ）在课 堂中思想抛针, 不听讲; 另有 $7 \%$ 的学生选择 逃课。在对学习计划的实施和坚持上, 有 $32 \%$ 的学生（其中民族学生占15\%) 表示实施过 但很快天折; $43 \%$ 的学生（其中民族学生占 18\%）表示实施过半后放弃; 仅有 $25 \%$ 的学生 （其中少数民族学生占 $11 \%$ ）表示实施并坚 持到最后。这一系列的数据体现我校大学生 对高等教育的重要性认识不深, $15 \%$ 的大学 生认为大学期间的学习较高中阶段放松。

(2) 自主学习能力令人堪忧。

课前预习是学生自己摸索、自己理解的 过程, 是提高学生自学能力的重要环节。调 查结果显示, $28 \%$ 的学生（其中民族学生占 15\%) 从不预习, 43\%的学生 (其中民族学生 占 $26 \%$ ) 偶尔有预习, $29 \%$ 的学生（其中少数 民族学生占 $8 \%$ ) 能长期坚持预习, 这说明大 多数学生的预习工作, 存在 “布置了就做, 没要求就不理” 的思想。在课后复习方面, 能够将当天内容进行归纳总结的学生占 $19 \%$ （其中少数民族学生占 $6 \%$ ）, 只是偶尔复习 的学生占 $67 \%$ （其中少数民族学生占 $30 \%$ ）, 有 $14 \%$ 的学生（其中民族学生占 $9 \%$ ）没有复 习的习惯。这表明很多学生忽视了及时复习 的重要性, 致使所学知识的系统性、完整性 受到破坏, 长此以往, 所学的知识就会模糊、 遗忘。如果别人不监督, 能主动学习的学生 只占 $39 \%$ （其中民族学生占 $12 \%$ ），另外，只 有 $51 \%$ 的学生（其中民族学生占 $5 \%$ ）能够独 立完成作业, 其余均存在不同程度的抄袭现 象。从这里可以看出, 我校大多数学生的学 
习积极主动性亟待提高 (与内地发达教育地 区而言）。

(3) 教与学脱节亟待改善。

学生对任课教师的授课有95\%的学生是 处在基本满意以上, 只有 $5 \%$ 的学生不满意。 但是对于经常与老师、同学就学习问题进行 讨论的问题上, 只有 7\%的学生 (其中民族学 生占 $4 \%$ ）经常交流， 85\%的学生（其中民族 学生占 $22 \%$ ）偶尔交流，8\%的学生（其中民 族学生占 $3 \%$ ）从不交流, 这表明民族学生对 待学习的热情和期望并不低于汉语言学生。 在学生参与课堂活动中, 仅有 $18 \%$ 的学生 (其 中民族学生占9\%）会积极参与，30\%的学生

(其中民族学生占 $10 \%$ ) 偶尔参与课堂活动, 高达 $52 \%$ 的学生 (其中民族学生占 $25 \%$ ) 从不 参与课堂活动, 这表明, 不少民族学生已经 被学习障碍阻挡。综上, 足以可见, 在长期 的传统教育影响下, 我校大多学生已习惯于 老师 “满堂灌”、学生 “满堂听” 的教学方 式, 学习成为单纯的传授知识而严重缺乏探 索研究, 学生在学习中提不出问题, 经常处 于无问题状态, 只能被动地接受, 教与学脱 节, 课堂变成教师的独角戏, 因此很难取得 良好的教学效果。

基于调查结果的统计分析, 民族地区大 学生学习主动性偏低, 其中民族学生学习主 动性意愿入学之初较高, 但持续性较差, 从 民族地区教育和民族人才培养的角度考虑， 民族地区的综合性大学应该对各民族大学 生学习主动性的缺乏问题引起高度重视, 并 且探索解决该问题的相关对策。

\section{四、影响民族地区大学生学习主动性的因}

\section{素}

从我校看, 影响少数民族大学生学习主 动性的因素主要来自两个方面: 学生自身的 主观原因和外部因素。

(1) 学生自身主观原因。

其一, 对于民族学生来说, 他们从小到 大说的是自己的语言 (个别除外), 进入学 校后, 基本上所有的科目都要用汉语授课, 语言上的不便使他们课程学习较吃力, 再加 上民族地区的自我竞争力较弱, 学生缺乏竞 争意识, 只有部分的同学真正渴望学习, 真 正为 “走出去” 而努力奋斗, 而不少学生为 了文凭, 为了不挂科而被动地学习, 导致最
终在学业上有所收获的学生少之又少, 这一 现象, 对我校汉语言学生也普遍基本存在。

其二, 学习动机和目标不清。学习动机 是影响学生学习主动性的重要内部因素, 它 决定了学生学习的基本方向, 能够激发学生 自我成就的愿望, 还有助于改变学生对学习 的消极态度, 从而提高学生对学习的主动 性。然而, 民族地区中的不少大学生缺乏明 确学习目标, 动力不强, 加之本身基础不好, 个别学生每天上课也会找借口开小差, 不认 真听讲, 时间一长, 恶性循环, 势必颓势无 法逆转。

其三, 专业选择之初的盲目性。莎士比 亚曾说过一句名言: “学问必须合乎自己的 兴趣, 方才可以得益”。由此可知, 大学生 主动学习的一个重要因素就是要对自己所 选择的事物感兴趣。我校每年申请跨院系转 专业的学生很多, 学校学院也做了大量工 作, 但是大学生对专业学习缺乏兴趣的仍不 少, 很重要的原因可以归结为学生对自己的 专业学习要求了解不清, 从而影响学习的主 动性。

(2) 外部因素。

其一，地域差距。不同的地区、不同的 民族有着不同的文化, 文化总是带着鲜明的 地域性特征。新疆位于祖国西部边陲, 地域 广衰, 千里不同风, 百里不同俗, 这决定了 新疆各地文化差异较大。在地域环境的影响 下, 形成了不同于其他地区学生的性格特征 以及思想观念和知识能力等。原因还是在于 我区学生受地势偏远、经济落后、文化制约 的影响, 教育发展的诸多问题长期得不到有 效的解决。例如: 对于居住在边远农村地区 的学生, 他们接触新鲜的事物较少, 知识面 较窄, 思想比较封闭, 小有成绩就会夜郎自 大, 从而容易产生满足感, 缺乏求知欲望。

其二, 家庭因素。都说父母是孩子的第 一位老师, 父母的言传身教在其子女学习目 的、学习态度、学习动机等方面常常起着潜 移默化的影响。然而, 由于我区群众文化素 质比较低, 对教育缺乏长远目光, 对教育的 长期投入、高投入难以理解, 对子女的教育 大学教育无法有效督促。

其三, 学校因素。民族地区教育是我国 整个教育发展重要而特殊的部分。其特殊性 
决定了从事少数民族地区教育事业教师的 光荣性、艰巨性、复杂性。在当前教育改革 的背景下, 教师在学生生活中扮演各种角 色, 兼有多种社会身份, 他们在教育教学中, 承担着多方面的社会责任, 老师的一举一动 都会影响到学生的一举一动, 所以作为民族 地区的教师, 一定要从学生的实际出发, 了 解学生学习、成长的特点做到因材施教尤 为重要。

\section{五、提高民族地区学生学习主动性的对策} 我区的教育不仅是一个单纯的教育问 题, 而且是一个关系到民族平等、民族团结 和共同繁荣的政治问题, 也是一个关乎和谐 社会建设的重要问题。我国民族地区的教育 急需大量人才投入, 因此, 应该在教育政策 上, 在教育形式上, 在教育内容上加快民族 地区大学教学变革, 促进民族地区大学教育 的发展, 提高民族地区大学生学习的主动 性。

\section{1. 政策机制，保障教育。}

经济与教育相互制约、相互联系, 所以 想要发展民族地区的教育最根本也是最直 接的措施是要加大对民族地区教育的投入。 从教育体制上保障学生平等普遍接受义务 制教育, 真正提高全区各民族人口素质。同 时也要积极推进教学内容和方法改革, 建立 一套完善的民族地区教育体系。

\section{2. 教学课程改革, 体现民族特色。}

我区教育一方面服务于我区的经济发 展, 另一方面是服务于继承和发扬民族的优 秀文化, 这是教育责无旁贷的义务。在多元 文化教育背景下, 我区教育内容除了包含现 有的科学文化知识外, 还应将独具特色的民 族传统文化融入其中, 结合学生的特点, 创 造性地设置一些选修课程, 比如, 民族音乐、 民族舞蹈、民族刺绣等民族艺术和民族工艺 课程, 打造具有民族特色的校园文化。在普 及民族文化方面, 充分利用实践活动课程进 行民族知识的教育, 让学生了解各民族的风 土人情等, 同时兼顾民族团结教育, 培养大 学生热爱家乡的情感, 激发民族自豪感、民 族认同感、民族归属感。把理想教育与民族 教育相结合, 整合民族文化资源, 沿着特色 办学的道路前行。

\section{3. 突出教学法, 促进学风。}

第一, 突出情感教育, 激发学生学习兴 趣。瑞士教育心理学家皮亚杰说过 “所有智 力方面的工作都要依赖兴趣, 兴趣是能量的 调节者, 它能支配内在动力, 促成目标的实 现”可见学生的学习如果没有兴趣就成了无 源之水, 无本之木。情感是一种无形的力量, 是激发学生求知欲的重要因素之一。因此, 教师不仅要努力培养自身广博的专业知识, 更要深入到学生中去, 与学生建立平等、融 洽的师生关系, 知道学生喜欢什么, 让学生 喜欢上自己的课, 愉快地接受课堂教学, 从 而提高教学质量。

第二, 发挥学生的主体作用, 营造良好 的学习氛围。加强优良学风建设, 在提高学 生思想意识的同时, 充分调动学生的主观能 动性, 促进学生自我教育, 自我管理, 形成 一种健康, 文明, 上进的班风, 增强集体荣 誉感, 加强学习小组内的合作交流, 集思广 益, 互相帮助, 共同提高学习实效, 以良好 的班风促进学风建设。与此同时, 鼓励竞争, 让学生结为竞争伙伴, 培养学生在超越他人 的基础上, 不断超越自我, 用竞争激发大学 生高昂的斗志, 发掘大学生巨大的学习潜 能。

第三, 创造条件, 提供学生自主探究学 习的机会。在课堂教学中, 教师应积极创造 条件, 促使学生主动探索、主动实践。并最 大限度地使学生动口、动手、动脑, 极大地 调动学生的主动性, 使他们在自主探索的过 程中真正理解知识和掌握方法, 这也正是所 强调的—— “以学生为主体, 把时间还给学 生, 把课堂的空间还给学生, 让学生充分

“动”起来” 的理念。

\section{六、结束语}

综上所述, 教育观念、教育内容、教育 形式等几个方面的建设是新时期民族地区 高等教育发展的关键所在。在“西部大开发” 的契机下, 只有全面、科学地了解大学生群 体, 采用与之匹配、讲求实效的综合教育模 式并通过教师教学方式的变化, 从而改善学 生的学习方式, 为大学生创造自由, 平等, 和谐的学习生活环境, 才能在真正意义上提 高大学生学习的主动性, 充分发挥学生的主 观能动性, 继而提高自身综合实力。 


\section{References}

[1] Zhu Yudong, Zhang Ying Qiang. Research on development strategy of newly set undergraduate disciplines in universities in western ethnic minority areas, Study on Higher Education, vol.15, 2014.

[2] Tang Haozhou. Thinking on the development of higher education in the western ethnic minority areas, Scientific and Technological Information (Academic Studies). vol.15, 2008.

[3] Li Xuejing. Innovating thinking on the reform and development of higher education in the western ethnic minority areas, Journal of Xinjiang Normal University (Philosophy and social science), vol.2, 2008.

[4] Liang Ying. The current situation, problems and countermeasures of higher education in ethnic minority areas in the western China, Journal of Mudanjiang Institute of Education, vol.2, 2009.

[5] Cheng Gensuo, Guo Jiandong, Gao Hui. The study and countermeasures on higher education in ethnic minority areas of China -- Taking Gansu Province as an example, Journal of Northwest Normal University (Social Science Edition), vol.15, 2011.

[6] Su Jianguo, Wang Ruiqin, Study on the cultivation of ethnic minority college students, Chinese and Foreign Entrepreneurs. vol.8, 2010.
[7] Liu Xinhua, Study on the cultivation of college students' learning initiatives, Study on New Curriculum(edition of middle month), vol.8, 2009.

[8] $\mathrm{Bu}$ Guanhao, Shi Chao. The countermeasures and reasons for the lack of active learning of contemporary college students, Science and Technology of Western China, vol 29, 2008.

[9] Hu Bingxian, Zhang Ziwei. The deviation of learning motivation and attribution analysis of ethnic minority college students, China Power Education, vol 22 , 2008.

[10] Li Yanyan. The study on learning motivation,needs, learning characteristics of ethnic minority college students -- Taking Sichuan Arts and Science College as an example, Theory Study, vol 14, 2014.

[11] Maimaitijiang Yiming. How to stimulate ethnic minority students' learning enthusiasm, Technology Information (Academic Research), vol 32, 2008.

[12] Hong Shengzhi, Wei Linjun. Ethnic minority students learning motivation deviation and countermeasures -- Based on the survey data of South Central National University, Success (Education). vol 6, 2013.

[13] Xing Duli, Qi Yanfang. An empirical study on ethnic minority students' learning strategy, Academic Journal of Lanzhou Polytechnic College. vol 3, 2011. 